\title{
Веретенникова В.Б. \\ Педагогическое наблюдение как метод развития базовых компетенций родителей в системе дошкольного образования
}

Автономное образовательное учреждение дополнительного образования Удмуртской Республики «Институт развития образования» doi: $10.18411 / \mathrm{sr}-10-02-2018-23$

(Россия, Ижевск)

idsp: 000001:sr-10-02-2018-23

\section{Аннотация}

Представлен опыт организационно-методического сопровождения курса «Управление качеством дошкольного образования» с элементами метода педагогического наблюдения направленного на развитие базовых компетенций родителей в условиях реализации федерального государственного образовательного стандарта дошкольного образования.

Ключевые слова: метод, педагогическое наблюдение, базовые компетенций, организация взаимодействия.

Согласно «Реестру примерной основной образовательной программы дошкольного образования» «программой предусмотрена система мониторинга динамики развития детей, основанная на методе наблюдения...». Дошкольной организации предоставляется право самостоятельного выбора методов и инструментов педагогического наблюдения для семьи ... [8].

Очевидно, что в сложившейся ситуации актуальным становится проблема обучения родителей осознанному выполнению своих функций по образованию детей на этапе детства.

Как отмечает Т.А. Куликова, семья является подсистемой общества и выполняет разнообразные социальные функции как первый и самый мощный воспитатель ребенка дошкольного возраста [7].

Разработанный нами курс «Управление качеством дошкольного образования»[3]используется в одной из дошкольных организаций г. Ижевска, предусматривает обучение взрослых и выступает как инструмент социального партнерства семьи и дошкольной организации. Целью курса является развитие базовых компетенций субъектов образовательного процесса в дошкольной организации в условиях реализации ФГОС ДО. Курс предназначен для организационно-методического сопровождения педагогов и родителей, предусматривающий проведение педагогического наблюдения, достоинством которого является реальный образовательный процесс, происходящий в динамике и регистрации достижений ребенка в социальной ситуации развития на этапе детства.

Рассматривая педагогическое наблюдение как метод, стимулирующий развитие у субъектов образовательного процесса (педагога, ребенка и родителей) базовых компетенций, целесообразно учитывать их структуру[5], представленную на рисунке 1.

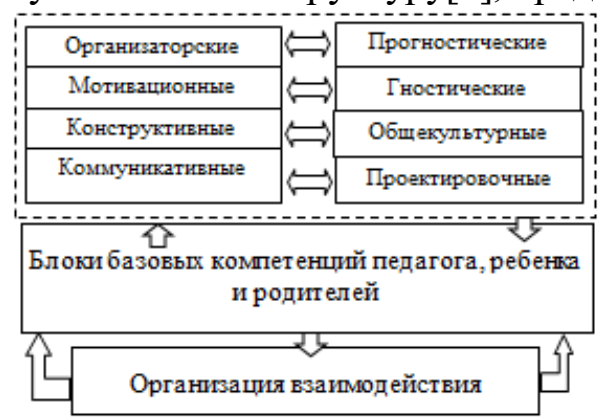

Рис. 1. Структура базовых компетенций субъектов образовательного процесса 
Она отражает обобщенные компетентностно-ориентированные цели субъектов образовательного процесса [4], направленные на реализацию задач ФГОС ДО и создания социальной ситуации для участия родителей в образовательной деятельности как равноправных социальных партнеров, осознающих равную с педагогами ответственность за образование детей.

В связи с этим, дошкольная организация создает единое пространство, которое имеет ключевое значение для обучения, воспитания дошкольника.

Здесь задаются направления образования, а сама семья, исходя из имеющихся у нее ресурсов (интеллектуальных, организаторских, материальных и т.д.), определяет степень участия в их реализации. В дошкольной организации предусматривается возможность индивидуализации на основе «вариативного развивающего образования, ориентированного на уровень развития,проявляющийся у ребенка в совместной деятельности со взрослыми и сверстниками, но не актуализирующийся в его индивидуальной деятельности (в зоне ближайшего развития)».

В период подготовки ребенка раннего возраста к дошкольной организации родители проводят педагогическое наблюдение, при которомвыявляются индивидуальныеособенности развития ребенка в семье.Родители заполняют Карту наблюдения № 1 (табл.1), в которой отмечаются режимные моменты дошкольной организации, соблюдаемые в домашних условиях, а также отслеживается эмоциональное состояние ребенка в течение дня, сформированность навыков самообслуживания, сон, аппетит и социальные контакты. Целью карты наблюдения является подготовка ребенка к дошкольной организации.

В пояснительной записке к карте наблюдения родителям предлагается понаблюдать за ребенком 2-3лет в домашних условиях. В колонке 1 они знакомятся с примерным режимом дня ребенка. В колонке 2 приведены показатели развития ребенка, если эти показатели присутствуют у ребенка в течение дня в домашних условиях, родителями ставится знак «+».

Исходя из этого, родителям предоставляется возможность в домашних условиях способствовать адаптации ребенка к режиму дошкольной организации и ознакомиться с консультациями: «Возрастные особенности развития детей первого-третьего года жизни» и «Индивидуальные особенности поведения детей в период адаптации» на сайте в папке педагога-психолога.

При этом системное педагогическое наблюдение за ребенком в домашних условиях создает условия для формирования и развития базовых компетенций родителя [1], представленные в таблице 2.

Наблюдение позволяет понять ребенка как личность, с тем, чтобы создавать для него комфортные условия адаптации к детскому саду и полностью отследить сформированные навыки самообслуживания (укладывания, засыпания, самостоятельности и опрятности, поведение во время еды, умение одеваться), поддерживать, поощрять его коммуникабельность и инициативу в познании окружающего пространства.

Взрослые наблюдают в домашних условиях за ребенком для того, чтобы увидеть изменения в их физическом, познавательном, социальном, эмоциональном развитии в течение всего времени подрастания, взаимодействия с ними и выбирают педагогические стратегии. При необходимости проводится коррекция по запросу родителей со специалистами ДОО с помощью индивидуальных консультаций (Skype),предварительно записавшись по электронной почте. 
Таблица 1

Фрагмент карты наблюдения за ребенком раннего возраста в домашних условиях

\begin{tabular}{|c|c|c|c|c|c|c|c|c|c|c|c|}
\hline Режимғые моменты & \multicolumn{11}{|c|}{ Эмоптионатьное состояние ребенка } \\
\hline \multirow[t]{2}{*}{1.} & \multicolumn{11}{|c|}{2.} \\
\hline & Весет & ПодвигенН & Улыбается & $\begin{array}{l}\text { Hacтроение } \\
\text { xороптее }\end{array}$ & Cпокоен & $\begin{array}{c}\text { Иногда } \\
\text { запумчाв }\end{array}$ & Замкнут & $\begin{array}{c}\text { Легкая } \\
\text { птаксивость }\end{array}$ & Хныканье & $\begin{array}{l}\text { Ситьный } \\
\text { птач }\end{array}$ & $\begin{array}{c}\text { Подавленноое } \\
\text { настроение }\end{array}$ \\
\hline \multicolumn{12}{|l|}{$\begin{array}{c}\text { Подъем, гигиенические } \\
\text { процедуры }\end{array}$} \\
\hline \multicolumn{12}{|l|}{ Утренняя гимнастика } \\
\hline \multirow{2}{*}{\multicolumn{12}{|c|}{ Подготовка к завтраку }} \\
\hline \multirow{2}{*}{\multicolumn{12}{|c|}{$\begin{array}{c}\text { Завтрак } \\
\text { Игры }\end{array}$}} \\
\hline & & & & & & & & & & & \\
\hline \multicolumn{12}{|l|}{ Подготовка к прогулке } \\
\hline \multicolumn{12}{|l|}{ Прогулка } \\
\hline \multirow{2}{*}{\multicolumn{12}{|c|}{ Возвращение с прогулки }} \\
\hline \multirow{2}{*}{\multicolumn{12}{|c|}{$\begin{array}{c}\text { Подготовка к обеду } \\
\text { Обед }\end{array}$}} \\
\hline & & & & & & & & & & & \\
\hline \multicolumn{12}{|l|}{ Подготовка ко сну } \\
\hline \multicolumn{12}{|l|}{ Дневной сон } \\
\hline \multicolumn{12}{|l|}{ Подъем ребенка, игры } \\
\hline \multirow{2}{*}{\multicolumn{12}{|c|}{$\frac{\text { Подготовка к полднику }}{\text { Полдник }}$}} \\
\hline & & & & & & & & & & & \\
\hline \multicolumn{12}{|l|}{ Игры } \\
\hline \multicolumn{12}{|l|}{ Подготовка к прогулке } \\
\hline \multicolumn{12}{|l|}{ Прогулка } \\
\hline \multirow{2}{*}{\multicolumn{12}{|c|}{$\frac{\text { Подготовка к ужину }}{\text { Ужин }_{\text {жй }}}$}} \\
\hline УжИн $_{\text {жй }}$ & & & & & & & & & & & \\
\hline Спокойные игры & & & & & & & & & & & \\
\hline Уктадывание, ночной сон & & & & & & & & & & & \\
\hline
\end{tabular}

Таблица 2

Фрагмент содержания базовых компетеничий родителей

\begin{tabular}{|c|c|c|}
\hline $\begin{array}{c}\text { Базовые } \\
\text { компетеничии }\end{array}$ & Код & Содержание \\
\hline \multirow[b]{2}{*}{ Проектировочные } & $\Pi 1$ & $\begin{array}{c}\underline{\text { Знаниеособенности ведущей деятельности детей дошкольного }} \\
\text { возраста }\end{array}$ \\
\hline & $\Pi 3$ & $\begin{array}{c}\text { Bладение навыком создания благоприятной домашней обстановки, } \\
\text { наполненной разнообразным игровым материалом в соответствие с } \\
\text { возрастом ребенка }\end{array}$ \\
\hline \multirow[t]{2}{*}{ Общекультурные } & $\mathrm{O} 2$ & 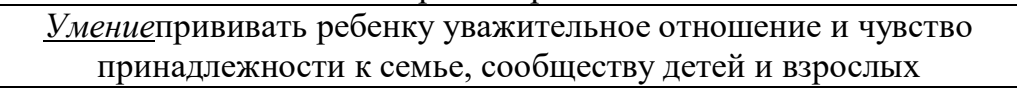 \\
\hline & O6 & Владение навыком речевого развития ребенка \\
\hline Прогностические & ПГ1 & 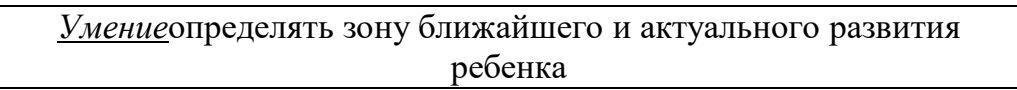 \\
\hline Гностические & $\Gamma 2$ & $\begin{array}{c}\text { Знаниеобщих закономерностей возрастного развития детей раннего } \\
\text { возраста }\end{array}$ \\
\hline \multirow{2}{*}{ Организаторские } & OP2 & $\begin{array}{c}\text { Умениеразъяснить ребенку правила безопасного поведения в быту, } \\
\text { социуме, на природе }\end{array}$ \\
\hline & OP5 & $\begin{array}{l}\text { Владение навыком моделирования режима дня ребенка, } \\
\text { уравновешивания его нервных процессовв течение дня }\end{array}$ \\
\hline Мотивационные & M1 & 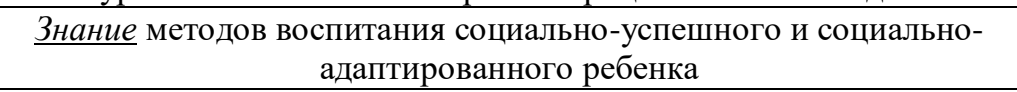 \\
\hline Конструктивные & K1 & $\begin{array}{c}\text { Умениеорганизовать игру ребенка и использовать возможности ее } \\
\text { социализирующего, обучающего, воспитывающего, развивающего } \\
\text { влияния }\end{array}$ \\
\hline Коммуникативные & KM2 & $\begin{array}{c}\text { Умение выстраивать партнерское взаимодействие с педагогами }_{\text {ДОО для решения образовательных, воспитательных и }} \\
\text { развивающих задач }\end{array}$ \\
\hline
\end{tabular}

Система семейного воспитания может быть стройной и упорядоченной, но при условии, что родители имеют определенную цель воспитания, проводят ее в жизнь, используя методы и средства воспитания, учитывающие особенности ребенка и перспективы его развития [7].

В период адаптации ребенка раннего возраста к дошкольной организации проводится заполнение журнала комплексной диагностикидостижений ребенка в индивидуальных образовательных траекториях [2] (табл.3). 
Таблица 3

Фрагмент журнала комплексной диагностики ребенка раннего возрастав индивидуальных образовательных траекториях

\begin{tabular}{|c|c|c|c|c|c|c|c|c|c|}
\hline \multirow{2}{*}{\multicolumn{2}{|c|}{$\begin{array}{l}\text { Инeapuamue } \\
\text { наячасть }\end{array}$}} & \multirow[t]{2}{*}{ HP } & \multirow[t]{2}{*}{$E K$} & \multirow[t]{2}{*}{$\begin{array}{l}\text { Содержсание базовых } \\
\text { компетенций ребенка }\end{array}$} & \multirow[t]{2}{*}{$\begin{array}{c}\text { Методы } \\
\text { исследования }\end{array}$} & \multirow[t]{2}{*}{ Диагностические задания } & \multicolumn{3}{|c|}{$\begin{array}{c}\text { Фиксирование достижский } \\
\text { ребенка в течение учебного } \\
\text { года }\end{array}$} \\
\hline & & & & & & & Начало & Cередина & Конег \\
\hline \multirow{5}{*}{ 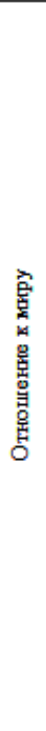 } & \multirow{5}{*}{ 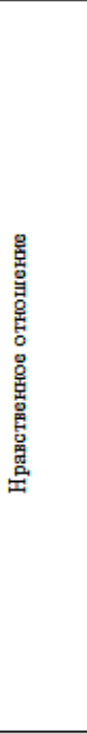 } & \multirow[t]{2}{*}{$\mathrm{CK}$} & \multirow[t]{2}{*}{0} & 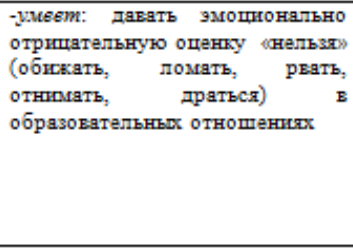 & 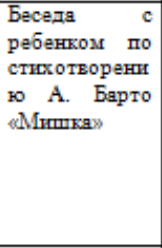 & 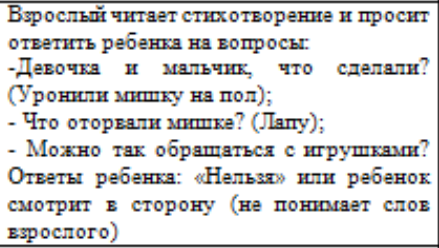 & & & \\
\hline & & & & $\begin{array}{l}\text { - умевет: вырахкать благодарность, } \\
\text { говорить "спаснбо» }\end{array}$ & $\begin{array}{l}\text { Наблюдение } \\
\text { во время еды }\end{array}$ & 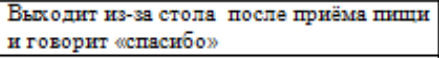 & & & \\
\hline & & \multirow[t]{2}{*}{$\Pi 3$} & $\mathrm{M}$ & $\begin{array}{l}\text {-умевт: проявить стремгление } \\
\text { бить хорошим в образовательной } \\
\text { деятельности }\end{array}$ & 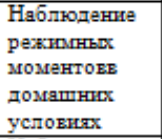 & 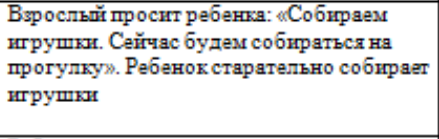 & & & \\
\hline & & & $\bar{K}$ & $\begin{array}{l}\text {-умевт: проявлять } \\
\text { эмопнональную сдержанность: } \\
\text { не кричит в обшественных } \\
\text { местах, не бегает по тротуару }\end{array}$ & $\begin{array}{l}\text { Наблюдение } \\
\text { на прогулке }\end{array}$ & $\begin{array}{l}\text { Ребенок прояеляет эмошиональную } \\
\text { сдержканность: не кричит, не бегает по } \\
\text { тротуару. Слушает взрослого }\end{array}$ & & & \\
\hline & & Pप & $\Gamma$ & $\begin{array}{l}\text {-умвет: отличать и назьпать } \\
\text { людей по принадлежности к } \\
\text { определенному полу в } \\
\text { соответствит с возрастом } \\
\text { (мальчи, дядл, дедушка, тетк, } \\
\text { бабушка, девочка) }\end{array}$ & $\begin{array}{l}\text { Беседа с } \\
\text { ребенком по } \\
\text { картинкам }\end{array}$ & 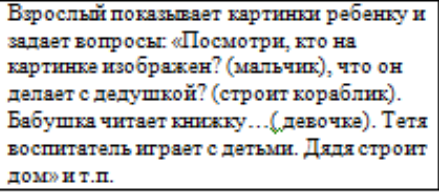 & & & \\
\hline
\end{tabular}

Для успешного изучения ребенка раннего возраста и использования его данных, с родителями проводится консультирование по вопросам применения методов и инструментария педагогического наблюдения. В ходе консультации родителей знакомятся с содержанием базовых компетенций ребенка, формами культурных практик и др. Педагог-психолог показывает папку с диагностическими заданиями, в которую входят: картинки разрезные из двух или трех частей, картинки парные, сюжетные картинки и т.п.

Внимание родителей акцентируют наразвивающем значении для ребенка раннего возраста диагностических заданий. В связи с этимвзрослым ребенка необходимо быть внимательным, сосредоточенным на общении и на наблюдении за ребенком в моменты совместной деятельности. Важно ребенку показать образец выполнения и обращать внимание на его достижения и индивидуальные проявления, а также на проблемные зоны развития, требующие педагогической поддержки взрослого.При этом все диагностические задания прописаны в рамках основной образовательной программы дошкольной организации.

В заключение педагог-психолог отвечает на вопросы родителей, договариваются о встрече через месяц с результатами в домашнем образовании. При заполнении журнала комплексной диагностики на практике используют теоретические знания возрастных особенностей ребенка раннего возраста и развиваются базовые компетенции родителя, а также корректируется стиль родительского воспитания. Наблюдение осуществляется ежедневно в течение месяца (сентябрь, январь, май). По результатам педагогического наблюдения осуществляется совместный анализ в рамках индивидуальных образовательных траекторий в дошкольной организации и в домашнем образовании. Наблюдение позволяет согласовывать мнения взрослых в образовательном процессе, которые видят одного и того же ребенка по-разному в рамках координации своих действий в соответствии с Договором по разделению ответственности при проектировании и реализации индивидуальной образовательной программы ребенка между дошкольной образовательной организацией и законными представителями.

Обобщая вышеизложенное, можно сделать вывод, что педагогическое наблюдение является методом обучения в организации взаимодействия с дошкольной организацией, 
обеспечивающий психолого-педагогическую поддержку семьи и повышение компетентности родителей в вопросах развития и образования ребенка в системе ДО. Именно такой метод обучения способствует повышению психолого-педагогической культуры родителей, от которой зависит успешность и результативность домашнего образования как вида образования, направленного на развитие личности ребенка в рамках индивидуальных образовательных траекторий на основе освоения образовательной программы дошкольной организации для достижения социально-нормативных возрастных характеристик в соответствии ФГОС ДО.

$$
* * *
$$

1. Веретенникова В. Б. Базовые компетенции субъектов образовательного процесса в системе современного дошкольного образования // Психология и педагогика: теоретические и практические аспекты современных наук : материалы XXXI междунар. науч.-практ. конф. - Москва. - 2015. - С 2738.

2. Веретенникова, В.Б. Индивидуальные образовательные траектории развития ребенка в системе дошкольного образования/ В.Б. Веретенникова // Качество Инновация Образование. - 2017. - № 1. C. $25-32$.

3. Веретенникова В.Б., Шихова О.Ф. Стратегические направления развития современной системы дошкольного образования// Современные проблемы науки и образования. - 2015. - № 6; URL: http://www.science-education.ru/130-23303 (дата обращения: 30.11.15)

4. Веретенникова В.Б. Структурно-функциональная модель качества компетентностно-ориентированного образовательного процесса в системе дошкольного образования/Казанский педагогический журнал. 2015. № 5. Часть 2. - С. 76-81.

5. Веретенникова В. Б. Структура компетенций субъектов образовательного процесса в современной системе дошкольного образования // Национальная Ассоциация Ученых. - 2015. - № 4-3 (9). - С. 69-72.

6. Веретенникова В. Б. Элементы дистанционного курса как средство обучения родителей в современной системе дошкольного образования // Тенденции науки и образования в современном мире. -2016 . - № 18-1. - C. 9-14.

7. Куликова Т. А. Семейная педагогика и домашнее воспитание : учебник. - Москва : Издательский центр «Академия», 1999. - 232 с.

8. Примерная основная образовательная программа дошкольного образования [Электронный ресурс] Режим доступа: http://gosreestr.ru/wp-content/uploads/2015/08/primernaja-osnovnaja-obrazovatelnajaprogramma-doshkolnogo-obrazovanija.pdf (15.09.2017).

\section{Иванова Н.В. \\ Роль средств массовой информации в решении проблемы суицида среди подростков}

Кубанский государственный университет физической культуры, спорта и туризма

(Россия, Краснодар)

doi: $10.18411 / s r-10-02-2018-24$

idsp: 000001:sr-10-02-2018-24

\section{Аннотация}

В статье представлен анализ эпидемиологии суицидов в мире, Российской Федерации, Краснодарском крае среди детей и подростков, приведены сведения, полученные в ходе анализа данных Всемирной организации здравоохранения, сформулированы причины различий между мужчинами и женщинами по частоте суицидов, представлена модель работы по профилактике самоубийств во всем мире. В работе также проанализированы среднестатистические показатели суицидов среди детей в возрасте 10-14 лет и молодежи 15-16 лет в Российской Федерации, Краснодарском крае, определена роль СМИ в решении проблемы суицида среди подростков. Сформулированы основные причины, влияющие на совершение самоубийств среди подростков.

Ключевые слова: средства массовой информации, суицид, подростки, молодежь 